\title{
The GRAPPA-OMERACT Working Group: 4 Prioritized Domains for Completing the Core Outcome Measurement Set for Psoriatic Arthritis 2019 Updates
}

\author{
Ying Ying Leung $\mathbb{D}^{\mathbb{D}}$, William Tillett ${ }^{\mathbb{D}}$, Ana-Maria Orbai ${ }^{(\mathbb{D})}$, Alexis Ogdie $\mathbb{D}^{\mathbb{D}}$, Lihi Eder $\mathbb{D}^{\mathbb{D}}$,

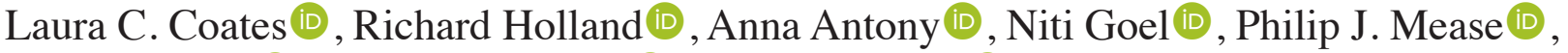 \\ Vibeke Strand (1D), Oliver FitzGerald (iD, Maarten de Wit (i), Christine A. Lindsay, \\ Kristina Callis Duffin (D), and Dafna D. Gladman (D)
}

\begin{abstract}
The Group for Research and Assessment of Psoriasis and Psoriatic Arthritis (GRAPPA)-Outcome Measures in Rheumatology (OMERACT) Psoriatic Arthritis (PsA) working group provided updates at the 2019 GRAPPA annual meeting on its work toward developing a core outcome set for PsA. The working group prioritized 4 domains, including musculoskeletal disease activity (enthesitis and dactylitis), fatigue, physical function, and structural damage. In this report, the working group summarizes its progress in standardizing the core outcome set for these 4 domains. (J Rheumatol Suppl. 2020 June;96:46-9; doi:10.3899/jrheum.200127)
\end{abstract}

Key Indexing Terms: PSORIATIC ARTHRITIS PSORIASIS OUTCOMEMEASURES GRAPPA OMERACT

From Duke-National University of Singapore (NUS) Medical School, Singapore, Department of Rheumatology and Immunology, Singapore General Hospital, Singapore; Royal National Hospital for Rheumatic Diseases, University of Bath, Bath, UK; Division of Rheumatology, Johns Hopkins University School of Medicine, Baltimore, Maryland; Perelman School of Medicine, University of Pennsylvania, Philadelphia, Pennsylvania, USA; Women's College Research Institute, Women's College Hospital, Department of Medicine, University of Toronto, Toronto, Ontario, Canada; Nuffield Department of Orthopaedics, Rheumatology and Musculoskeletal Sciences, University of Oxford, Oxford, UK; Concord Repatriation General Hospital, Sydney, Australia; Monash University School of Clinical Sciences, Monash Medical Centre, Clayton, Melbourne, Australia; Caduceus Biomedical Consulting LLC, Raleigh; Duke University School of Medicine, Durham, North Carolina; Rheumatology Research, Swedish Medical Center/Providence St. Joseph Health and University of Washington School of Medicine, Seattle, Washington; Division of Immunology/Rheumatology, Stanford University School of Medicine, Palo Alto, California, USA; Conway Institute for Biomolecular Research, University College Dublin, Dublin, Ireland; Double X Management Inc., Prosper, Texas; Department of Dermatology, University of Utah, Salt Lake City, Utah, USA; University of Toronto, Krembil Research Institute, and Psoriatic Arthritis Program, University Health Network, Toronto Western Hospital, Toronto, Ontario, Canada.

As part of the supplement series GRAPPA 2019, this report was reviewed internally and approved by the Guest Editors for integrity, accuracy, and consistency with scientific and ethical standards.

Y.Y. Leung is funded by the Clinician Scientist award of the National Medical Research Council, Singapore (NMRC/CSA-INV/0022/2017). The views expressed are those of the author(s) and not necessarily those of the NMRC. A.M. Orbai is funded by the Jerome L. Greene Foundation Scholar Award, the Staurulakis Family Discovery Award, the Rheumatology Research Foundation, and the US National Institutes of Health (NIH) through the Rheumatic Diseases Resource-based Core Center (P30-AR053503, Cores A and D; and P30-AR070254, Cores A and B). All statements in this report, including its findings and conclusions, are solely those of the authors and do not necessarily represent the views of the NIH the US National Institute of Arthritis Musculoskeletal and Skin Diseases (NIAMS), or the Rheumatology Research Foundation (RRF). A. Ogdie is funded by the RRF and NIH/NIAMS K23 AR063764 and RO1 AR072363. L.C. Coates is funded by an NIH Research (NIHR) Clinician Scientist award. The research was supported by the NIHR Oxford Biomedical Research Centre. The views expressed are those of the author $(s)$ and not necessarily those of the NHS, the NIHR, or the UK Department of Health. Y.Y. Leung, MB ChB, MD, Associate Professor, Duke-NUS Medical School, and Department of Rheumatology and Immunology, Singapore General Hospital; W. Tillett, BSc, MB ChB, PhD, MRCP, Consultant Rheumatologist, Senior Lecturer, Royal National Hospital for Rheumatic Diseases, University of Bath; A.M. Orbai, MD, MHS, Assistant Professor of Medicine, Director Psoriatic Arthritis Program, Division of Rheumatology, Johns Hopkins University School of Medicine; A. Ogdie, MD, MSCE, Associate Professor of Medicine and Epidemiology, Perelman School of Medicine, University of Pennsylvania; L. Eder, MD, PhD, Women's College Research Institute, Women's College Hospital, Department of Medicine, University of Toronto; L.C. Coates, MB ChB, PhD, NIHR Clinician Scientist, Nuffield Department of Orthopaedics, Rheumatology and Musculoskeletal Sciences, University of Oxford; R. Holland, MBBS, Concord Repatriation General Hospital; A. Antony, MBBS, Monash University School of Clinical Sciences, Monash Medical Centre; N. Goel, MD, Patient Research Partner, Consultant, Caduceus Biomedical Consulting LLC, and Adjunct Assistant Professor, Duke University School of Medicine; P.J. Mease, MD, Rheumatology Research, Swedish Medical Center/Providence St. Joseph Health and University of Washington School of Medicine; V. Strand, MD, Division of Immunology/ Rheumatology, Stanford University School of Medicine; O. FitzGerald, $M D, F R C P I, F R C P(U K)$, Consultant Rheumatologist and Newman Clinical Research Professor, Conway Institute for Biomolecular Research, University College Dublin; M. de Wit, PhD, Patient Research Partner, Amsterdam, the Netherlands; C.A. Lindsay, PharmD, Patient Research Partner, President, Double X Management Inc.; K. Callis Duffin, MD, $M S$, Department of Dermatology, University of Utah; D.D. Gladman, $M D$, FRCPC, Professor of Medicine, University of Toronto, Senior Scientist, Krembil Research Institute, and Director, Psoriatic Arthritis Program, University Health Network, Toronto Western Hospital.

Address correspondence to Associate Prof. Y.Y. Leung, Department of Rheumatology and Immunology, Singapore General Hospital, 20 College Road, the Academia, Singapore S169856.E-mail:katyccc@hotmail.com

Personal non-commercial use only. The Journal of Rheumatology Copyright @ 2020 . All rights reserved. 
In 2016, the Group for Research and Assessment of Psoriasis and Psoriatic Arthritis (GRAPPA)-Outcome Measures in Rheumatology (OMERACT) Psoriatic Arthritis (PsA) Core Set working group updated the Core Domain Set ${ }^{1,2}$. The updated Core Domain Set was developed through a combined effort of healthcare professionals and patient research partners (PRP), who defined essential domains to be measured in all clinical trials ${ }^{1,2}$. Since then, the working group has initiated the development of a PsA Core Outcome Measurement $\mathrm{Set}^{3}$. During the 2018 OMERACT meeting in Terrigal, Australia, the 66/68 swollen and tender joint count was endorsed to measure the domain of "musculoskeletal (MSK) disease activity: peripheral joints ${ }^{4}$," and the PsA Impact of Disease 12-item questionnaire (PsAID-12) received provisional endorsement for measurement of the domain of health-related quality of life ${ }^{5}$.

The working group prioritized 4 additional domains to undergo instrument appraisal, including 2 subdomains of MSK disease activity (enthesitis and dactylitis), fatigue, physical function, and structural damage. These 4 domains were chosen due to their importance in clinical trials, their effect on patients, and the urgent need to standardize the use of instruments to assess the domains ${ }^{6}$. This is a report of the working group's presentation at the GRAPPA 2019 annual meeting in Paris, France, where the work undertaken to standardize the Core Outcome Set for these 4 domains was presented.

\section{Overall Work Stream for Each Domain}

Dr. Ying Ying Leung explained that the appraisal of instruments for each domain follows the methodology laid out in the OMERACT Filter $2.1^{6}$. The 4 pillars of the OMERACT Filter 2.1 consist of Truth 1 (Domain Match), Feasibility, Truth 2 (Numerical Sense), and Discrimination ${ }^{7}$. The overall work stream for each of the 4 domains starts by convening a domain working group. Members of each domain working group comprise healthcare professionals with relevant expertise and at least 2 PRP. Relevant instrument(s) for the domains are then identified through systematic literature reviews (SLR) and working group input. For domains that have numerous instruments available, the domain working groups may prioritize instruments through discussion and Delphi exercises to achieve consensus. Prioritized instruments for a domain are then critically appraised using the OMERACT Filter 2.1.

The working group has already developed and used specific methods for PRP to evaluate domain match and feasibility. The appraisal processes with the OMERACT Filter 2.1 for each instrument will be discussed with the OMERACT technical advisory group once the evidence supporting an instrument is collected. The evidence supporting each instrument for a domain will be provided in the OMERACT summary of measurement properties table. For some instruments, missing evidence may need to be acquired.
The domain working groups will consider the evidence supporting each instrument and develop consensus through Delphi exercises. All supporting documentation for each instrument will be submitted to OMERACT as an instrument workbook. The OMERACT technical advisory group will work with the domain working groups on the recommendation of instruments based on the results of the instrument workbooks. This new virtual method will enable the OMERACT community to endorse instruments as information becomes available, rather than having to wait for the standard voting workshop during the biennial OMERACT congress.

\section{Updates on Work Stream for Each Prioritized Domain}

MSK disease activity: enthesitis and dactylitis. Dr. Alexis Ogdie led the MSK disease activity working group, which included 3 PRP. The working group completed an SLR of the instruments that measure dactylitis, enthesitis, and peripheral joint counts in March 2017. The summary from the peripheral joint studies has now been published ${ }^{4}$. Since the OMERACT 2018 meeting, the working group has been assembling similar summaries of the measurement property tables for enthesitis and dactylitis. Disease activity in the axial spine is not prioritized here. GRAPPA and the Assessment of Spondyloarthritis international Society are collaborating to develop classification criteria for axial PsA that can be more routinely and reliably assessed in clinical trials and in practice. Historically, axial spondyloarthritis (SpA) outcome measures have been applied when assessing axial involvement in PsA without validation ${ }^{8}$. Development of axial assessments for PsA remains an active research agenda item. Fewer studies have investigated the psychometric properties of the measurement tools for these disease features. Next steps will include a Delphi exercise similar to that performed for the joint counts. This exercise will also include patient engagement to understand the content validity and feasibility of the enthesitis and dactylitis measures from the patient perspective.

Enthesitis can also be assessed using ultrasound. Dr. Lihi Eder is leading an independent working group focused on the measurement properties of sonographic-assessed enthesitis ${ }^{9}$. This working group performed an SLR on sonographic enthesitis scoring instruments ${ }^{9}$. A few sonographic enthesitis scoring instruments that were developed for SpA were identified to assess enthesitis, but most have not been validated in PsA. None of these instruments has the potential to pass the OMERACT Filter 2.1. Therefore, additional research is required before existing instruments for enthesitis ultrasound assessment can be endorsed.

Fatigue. Fatigue is a PsA core domain that is variably measured in PsA clinical trials ${ }^{10}$. Evidence supporting fatigue instruments in PsA is summarized in the SLR of patient-reported outcome measures $(\mathrm{PROM})^{11}$. The instruments with psychometric evidence in PsA were the Functional

Personal non-commercial use only. The Journal of Rheumatology Copyright @ 2020 . All rights reserved. 
Assessment of Chronic Illness Therapy (FACIT)-Fatigue scale, Fatigue visual analog scale (VAS), Fatigue numerical rating scale (NRS), and the vitality domain of the Medical Outcome Study Short Form-36 (SF-36) health survey. New evidence has emerged for fatigue instruments in PsA since the publication of the SLR, including randomized controlled trial (RCT) thresholds for improvement for FACIT-Fatigue ${ }^{12}$ and the Fatigue $\mathrm{NRS}^{13}$, as well as the FACIT-Fatigue content validity. A challenge for the appraisal of VAS and NRS single items is the standardization of the wording and time interval (e.g., past 7 days, today).

Dr. Ana-Maria Orbai is convening a fatigue working group that will consider the fatigue instruments identified above ${ }^{11}$, as well as instruments used in prior PsA studies such as the Fatigue Severity Score, Fatigue Assessment Scale, Patient Reported Outcomes Measurement Information System (PROMIS)-Fatigue, and single fatigue items included in the Bath Ankylosing Spondylitis Disease Activity Index and PsAID questionnaires ${ }^{10}$. Similar to the prioritization process undertaken for the physical function domain, the working group will use discussion and Delphi exercises to set priorities for instruments that will undergo further evaluation using the OMERACT Filter 2.1.

Physical function. The physical function working group is led by Dr. Leung and consists of 13 members, including 2 PRP. The working group has international representation that spans North America, Asia, and Europe. Based on data from a published SLR on PROM in PsA ${ }^{11}$, the working group identified a list of PROM that measure physical function for PsA and recommended additional, newer instruments. Based on the working concept and definition of physical function as the perception of physical capability ${ }^{14}$, the working group decided to focus on PROM instead of performance-based assessments. Through discussions and 2 rounds of Delphi exercises, the working group prioritized 6 PROM that will be further appraised individually using the OMERACT Filter 2.1. These 6 PROM are the Health Assessment Questionnaire-Disability Index (HAQ-DI), HAQ-Spondyloarthropathies, modified HAQ, multidimensional HAQ, the physical functioning domain of the SF-36 (SF-36-PF), and the PROMIS-Physical Function questionnaire $^{14 a}$. The working group is conducting an SLR to evaluate the discrimination of various PROM for physical function in RCT.

The appraisal document for the HAQ-DI was submitted to OMERACT for virtual voting, and the SF-36-PF will also be appraised next. The other PROM will require acquisition of new data before they are formally evaluated using the OMERACT Filter 2.1.

Structural damage. William Tillett and Anna Antony reviewed progress by the structural damage working group. Unlike domains in the inner circle, which are mandatory in all RCT, the assessment of structural damage is placed in the middle circle of the Core Domain Set. Inhibition of structural damage is seen as important to be demonstrated at least once during drug development but not required to be measured in all clinical trials ${ }^{2}$. As a result, the OMERACT working group has prioritized structural damage for the selection of measurement instruments despite its position in the middle circle of the Core Domain Set. The structural damage working group is conducting an SLR of imaging instruments for the assessment of structural damage in PsA. The group discussed how the SLR data should be reported and agreed that data that relate to plain radiographic instruments would be reported first, followed by the other imaging modalities, including magnetic resonance imaging, ultrasound, and computed tomography.

\section{Composites}

Composite indices are commonly used in rheumatology for the combined assessment of disease as well as for defining a treatment target or disease state. They typically span several domains to encompass a broader concept of disease activity and disease effect. Several composite indices have been developed specifically for PsA and are used in $\mathrm{RCT}^{15}$, but consensus on which instrument to take forward is not available ${ }^{16}$. In addition, the process for validation of composite indices is yet to be clarified within OMERACT. A workshop on composite indices in PsA was undertaken at the GRAPPA 2019 annual meeting and is reported separately ${ }^{17}$.

This report summarizes the GRAPPA-OMERACT PsA Core Set working group's efforts to develop a standardized Core Outcome Set. The working group described 4 prioritized domains: MSK disease activity (enthesitis and dactylitis), fatigue, physical function, and structural damage. Each domain working group summarized its progress to standardize the Core Outcome Set for these 4 domains.

\section{REFERENCES}

1. Orbai AM, de Wit M, Mease PJ, Callis Duffin K, Elmamoun M, Tillett W, et al. Updating the psoriatic arthritis (PsA) core domain set: a report from the PsA workshop at OMERACT 2016. J Rheumatol 2017;44:1522-8.

2. Orbai AM, de Wit M, Mease P, Shea JA, Gossec L, Leung YY, et al. International patient and physician consensus on a psoriatic arthritis core outcome set for clinical trials. Ann Rheum Dis 2017; 76:673-80

3. Tillett W, Orbai AM, Ogdie A, Leung YY, Strand V, Gladman DD, et al; GRAPPA OMERACT Psoriatic Arthritis working group. GRAPPA-OMERACT initiative to standardise outcomes in psoriatic arthritis clinical trials and longitudinal observational studies. Ann Rheum Dis 2018;77:e23.

4. Duarte-Garcia A, Leung YY, Coates LC, Beaton D, Christensen R, Craig ET, et al. Endorsement of the 66/68 joint count for the measurement of disease activity: OMERACT 2018 psoriatic arthritis workshop report. J Rheumatol 2019;46:996-1005.

5. Orbai AM, Holland R, Leung YY, Tillett W, Goel N, Christensen R, et al. PsAID12 provisionally endorsed at OMERACT 2018 as core outcome measure to assess psoriatic arthritis-specific health-related quality of life in clinical trials. J Rheumatol 2019;46:990-5.

6. Leung YY, Orbai AM, Ogdie A, Coates LC, de Wit M, Callis Duffin $\mathrm{K}$, et al. The GRAPPA-OMERACT psoriatic arthritis working

Personal non-commercial use only. The Journal of Rheumatology Copyright $(\subset) 2020$. All rights reserved. 
group at the 2018 annual meeting: report and plan for completing the core outcome measurement set. J Rheumatol Suppl 2019; 95:33-7

7. Boers M, Kirwan JR, Tugwell P, Beaton D, Bingham CO 3rd, Conaghan PG. The OMERACT handbook. [Internet. Accessed February 10, 2020.] Available from: omeracthandbook.org

8. Mease PJ. Measures of psoriatic arthritis: tender and swollen joint assessment, Psoriasis Area and Severity Index (PASI), Nail Psoriasis Severity Index (NAPSI), Modified Nail Psoriasis Severity Index (mNAPSI), Mander/Newcastle Enthesitis Index (MEI), Leeds Enthesitis Index (LEI), Spondyloarthritis Research Consortium of Canada (SPARCC), Maastricht Ankylosing Spondylitis Enthesis Score (MASES), Leeds Dactylitis Index (LDI), patient global for psoriatic arthritis, Dermatology Life Quality Index (DLQI), Psoriatic Arthritis Quality of Life (PsAQOL), Functional Assessment of Chronic Illness Therapy-Fatigue (FACIT-F), Psoriatic Arthritis Response Criteria (PsARC), Psoriatic Arthritis Joint Activity Index (PsAJAI), Disease Activity in Psoriatic Arthritis (DAPSA), and Composite Psoriatic Disease Activity Index (CPDAI). Arthritis Care Res 2011;63 Suppl 11:S64-85.

9. Elalouf O, Bakirci Ureyen S, Touma Z, Anderson M, Kaeley GS, Aydin SZ, et al. Psoriatic arthritis sonographic enthesitis instruments: a systematic review of the literature. J Rheumatol 2019;46:43-56.

10. Kalyoncu U, Ogdie A, Campbell W, Bingham CO 3rd, de Wit M, Gladman DD, et al. Systematic literature review of domains assessed in psoriatic arthritis to inform the update of the psoriatic arthritis core domain set. RMD Open 2016;2:e000217.

11. Hojgaard P, Klokker L, Orbai AM, Holmsted K, Bartels EM, Leung YY, et al. A systematic review of measurement properties of patient reported outcome measures in psoriatic arthritis: a
GRAPPA-OMERACT initiative. Semin Arthritis Rheum 2018;47:654-65.

12. Cella D, Wilson H, Shalhoub H, Revicki DA, Cappelleri JC, Bushmakin AG, et al. Content validity and psychometric evaluation of functional assessment of chronic illness therapy-fatigue in patients with psoriatic arthritis. J Patient Rep Outcomes 2019;3:30

13. Gladman D, Nash P, Goto H, Birt JA, Lin CY, Orbai AM, et al. Fatigue numeric rating scale validity, discrimination and responder definition in patients with psoriatic arthritis. RMD Open 2020;6:e000928.

14. Holland R, Tillett W, Ogdie A, Leung YY, Gladman DD, Callis Duffin K, et al. Content and face validity and feasibility of 5 candidate instruments for psoriatic arthritis randomized controlled trials: the PsA OMERACT core set workshop at the GRAPPA 2017 annual meeting. J Rheumatol Suppl. 2018 Jun;94:17-25.

15. Coates LC, Mumtaz A, Helliwell PS, Mease PJ, Callis-Duffin K, Krueger GG, et al. Development of a disease severity and responder index for psoriatic arthritis (PsA)--report of the OMERACT 10 PsA special interest group. J Rheumatol 2011;38:1496-501.

16. Coates LC, FitzGerald O, Merola JF, Smolen J, van Mens LJJ, Bertheussen H, et al. Group for Research and Assessment of Psoriasis and Psoriatic Arthritis/Outcome Measures in Rheumatology consensus-based recommendations and research agenda for use of composite measures and treatment targets in psoriatic arthritis. Arthritis Rheumatol 2018;70:345-55.

17. Tillett W, McHugh N, Orbai AM, Ogdie A, Leung YY, Coates L, et al. Outcomes of the 2019 GRAPPA workshop on continuous composite indices for the assessment of psoriatic arthritis and membership-recommended next steps. J Rheumatol Suppl 2020 Jun;96:11-18 